\title{
Cutaneous tuberculosis with nonreactive PPD skin test: a diagnostic challenge*
}

\author{
Priscila Wolf Nassif ${ }^{1}$ \\ Ana Cristina Medeiros Gurgel ${ }^{1}$ \\ José Fillus Neto ${ }^{3}$
}

\author{
Ana Paula Zanatta Rosa ${ }^{1}$ \\ Paula Aline Zanetti Campanerut ${ }^{2}$ \\ Rosilene Fressatti Cardoso²
}

Abstract: The authors report a case of cutaneous tuberculosis in a 63-year-old female patient, who had an infiltrated, erythematous-ferruginous plaque of indurated aspect on her right leg and a nonreactive PPD skin test. Diagnosis was made by tissue culture and PCR of skin biopsy material. The treatment was performed with pyrazinamide, rifampicin, isoniazid and ethambutol, with good response.

Keywords: Mycobacterium tuberculosis; Tuberculosis; Tuberculosis, cutaneous

A 63-year-old female patient had an indurated, infiltrated erythematous-ferruginous plaque with central atrophic scars (from previous biopsies) on her right leg (Figure 1). She had been treated with antibiotics, antifungal and corticosteroid therapy with no improvement. We repeated the biopsy and the lesion progressed to a 6-cm ulcer with irregular borders and fibrino-necrotic areas (Figure 2). The following tests were normal: blood cell count, VDRL, ANA, AFB in the lymph nodes, HIV, culture for bacteria and fungi (in biopsy material), serology for leishmaniasis, and radiography of the chest and legs. ESR was 48 $\mathrm{mm} /$ hour and PPD was nonreactive. The anatomicopathological study showed histiocytes and multinucleated giant cells (Figure 3). Culture was positive for AFB. PCR (polymerase chain reaction) revealed genotypic characters of Mycobacterium tuberculosis (primers TB1 (primers: TB1 (5'-CCTGCGAGCGTAGGCGTCGG-3') and TB2 (5'-CTCGTCCAGCGC-

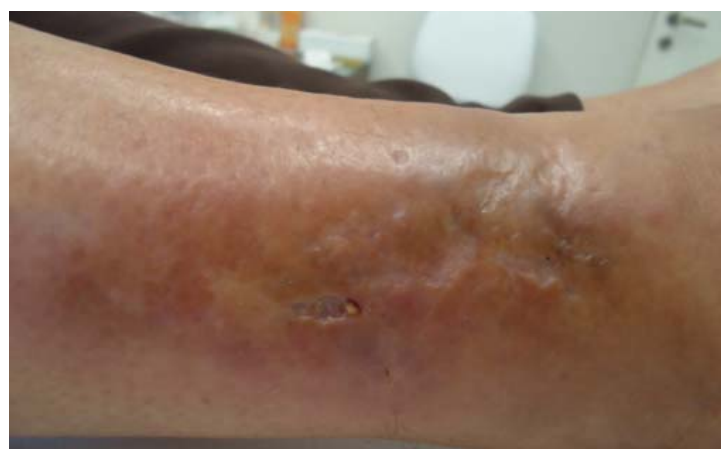

FIGURE 1: Indurated erythematous-ferruginous plaque with central atrophic scars (from previous biopsies) on the lateral side of the right leg

CGCTTCGG-3')), which amplify a fragment of 123 base-pairs (bp) of the IS6110 sequence (Figure 4). The treatment was performed with pyrazinamide, rifampicin, isoniazid and ethambutol. 


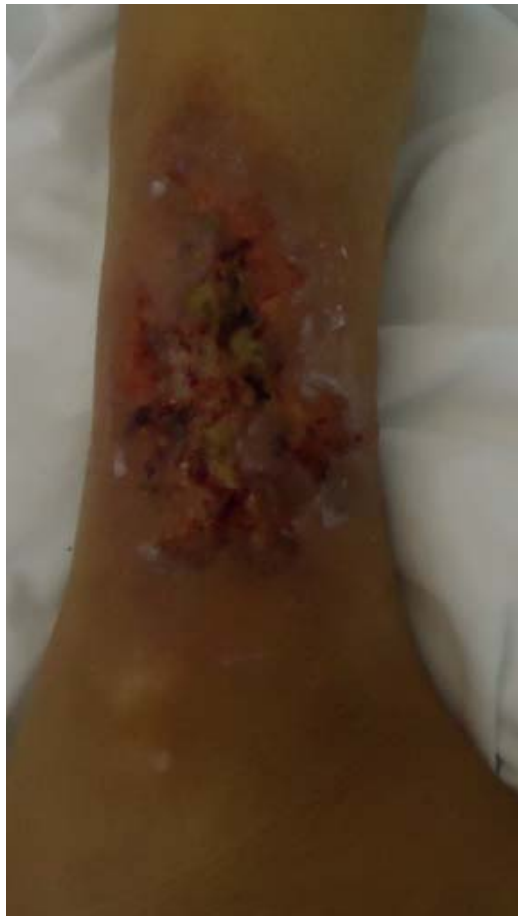

FIGURE 2:

Ulcer with irregular borders and center with areas of necrosis and fibrin on the lateral side of the right leg

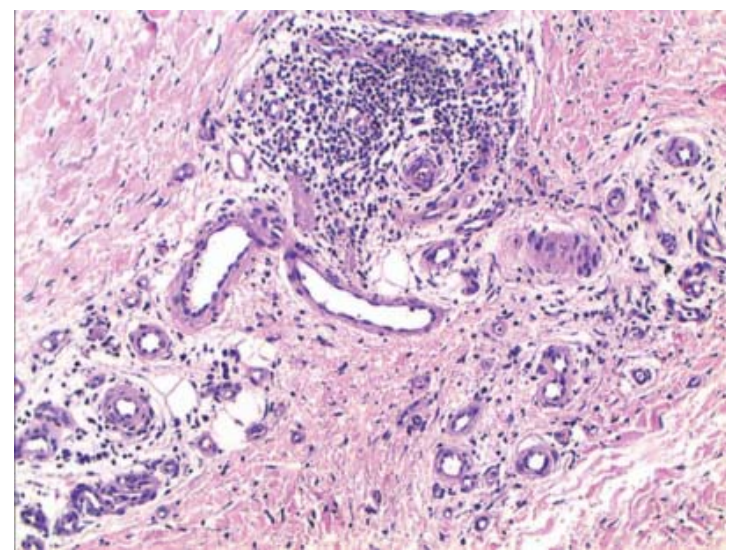

Figure 3: H.E. Areas of granulation tissue with foci of lymphocytic inflammatory infiltrate and associated fibrosis are seen in the dermis

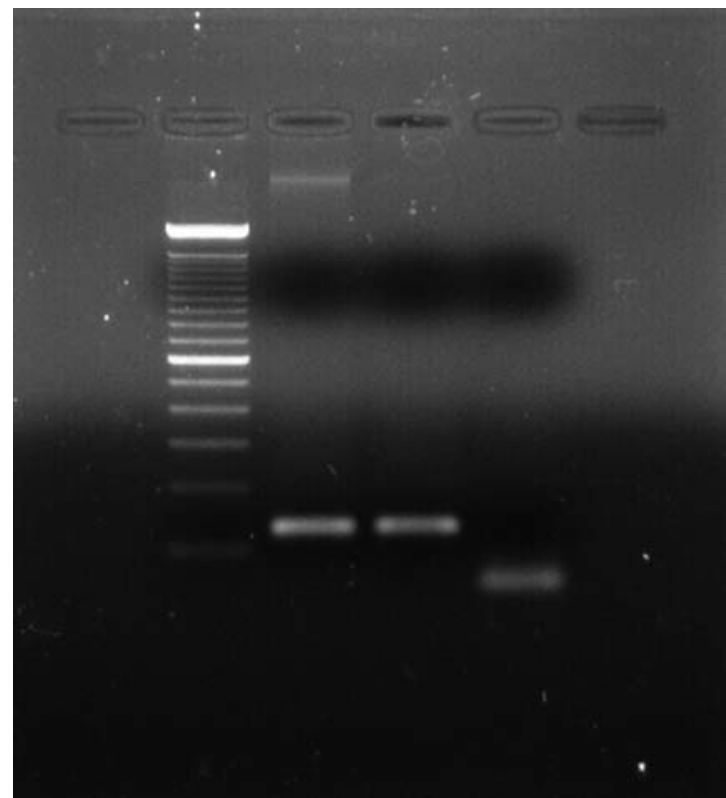

FIGURE 4: Electrophoresis in agarose gel of the PCR products. Lane M, molecular weight marker (100 bp ladder); lane 1, PCR product obtained from the patient's sample (positive for M. tuberculosis). Lane 2, positive control (M. tuberculosis); lane 3, negative control

\section{DISCUSSION}

Cutaneous tuberculosis (CT) accounts for 1.5\% of cases of extrapulmonary tuberculosis. ${ }^{1}$ It may be acquired through exogenous inoculation or endogenous spread. ${ }^{2}$ The tuberculous chancre is exogenously acquired and develops after inoculation of $M$. tuberculosis into the skin. PPD skin test is usually negative, compatible with the clinical presentation. ${ }^{3}$ The following tests are used for the diagnosis of CT: culture, PCR, bacterioscopy, histopathology and PPD.,5 Attention should be paid to PPD skin test, since it can be negative in patients with tuberculous chancre, tuberculous gumma or miliary $\mathrm{CT}$, or viral infections; in patients treated with immunosuppressants or corticosteroids; in advanced age or pregnant patients; in patients with myeloproliferative diseases, malnutrition, sarcoidosis, idiopathic hypothyroidism or hypothyroidism after isoniazid therapy ?3,6,7 


\section{REFERENCES}

1. Chaudhari ND, Talaniker HV, Deshmukh P, Supta S. A clinicopathological study of cutaneous tuberculosis at Pune district, Maharashtra. Int J Pharm Biomed. 2012;3:181-3.

2. Ifitkharr U, Naddem M, Aman S, Kazmi AH. Scrofuloderma: a common type of cutaneous tuberculosis. A case report. Journal of Pakistan Association of Dermatologist. 2011;21:61-5.

3. Ramos-e-Silva M, Castro MCR. Infecções por Mlcobactérias. In: Bologna JL, Jorizzo JL, Rapini RP. Dermatologia. Rio de janeiro: Elsevier; 2011. p. 1114-7.

4. Almaguer CJ, Ocampo CJ, Rendon A. Current panorama in the diagnosis of cutaneous tuberculosis. Actas Dermosifiliogr. 2009;100:562-70.

5. Ferreira CP, Ruas SC, Borges MM, Oliveira CAB, Ferreira JA, Lima RB, et al. Tuberculose pulmonar e cutânea em paciente HIV positivo. Pulmão RJ. 2004;13:122-6.

6. Sehgal VN, Wagh SA. Cutaneous Tuberculosis. Current concepts. Int J Dermatol 1990;29:237-49.

7. Diógenes MJN, Meireles TEF, Cabral SEX, Carvalho FF, Silva MAB, Almeida EP, et al. Tuberculose cutânea: avaliação retrospectiva (1981 a 1990). An Bras Dermatol. 1996; $71: 107-13$

\author{
MAILING ADDRESS: \\ Priscila Wolf Nassif \\ Av Rio Branco, 852 \\ 87015-380 - Maringá - PR \\ Brazil \\ E-mail: priwolf@gmail.com
}

How to cite this article: Nassif PW, Rosa APZ, Gurgel ACM, Campanerut PAZ, Fillus Neto J, Cardoso RF. Cutaneous tuberculosis with nonreactive PPD skin test: a diagnostic challenge. An Bras Dermatol. 2015;90(1):128-30. 